\title{
Contribution of growing-up milks to the diets of Irish children aged 12-36 months
}

\author{
J. Walton and A. Flynn \\ School of Food \& Nutritional Sciences, University College Cork, Republic of Ireland
}

Over the last decade, growing-up milks have become available commercially in Ireland for children aged 12-36 months to complement a balanced diet and to help reduce the risk of nutrient inadequacies. The aim of this paper is estimate the intake and contribution to the energy and nutrient intakes of growing-up milks in Irish children aged 12-36 months. Analyses were based on data from the National Pre-School Nutrition Survey (2010-2011), a nationally representative survey of food consumption in 1-4 year old Irish children (www.iuna.net). A 4-day weighed food diary was used to collect food intake data and nutrient intakes were estimated using WISPC), which is based on McCance and Widdowson's The Composition of Foods $6^{\text {th }}$ edition $^{(1)}$ and the Irish food composition database ${ }^{(2)}$. Growing-up milks were consumed by $20 \%$ of children aged $12-36$ months (12-24m: $25 \%$; $24-36$ m: $14 \%)$ with an average daily intakes among consumers of $360 \mathrm{ml}$ for 12-24 month olds and $298 \mathrm{ml}$ for $24-36$ month olds. The table below presents the contribution of growing-up milks to mean daily energy and nutrient intakes in consumers only $(n=49)$.

\begin{tabular}{|c|c|c|c|}
\hline & \multirow{2}{*}{$\frac{\text { Daily intake }}{\text { Mean }}$} & \multicolumn{2}{|c|}{ Contribution of growing-up milks } \\
\hline & & Mean & $\%$ \\
\hline Energy (kcal) & 1113 & 222 & 21.5 \\
\hline Protein $(\mathrm{g})$ & 39.5 & 5.2 & 14.7 \\
\hline Fat $(\mathrm{g})$ & 42.3 & 9.2 & 24.8 \\
\hline Saturated Fat (g) & 17.3 & 2.2 & 15.5 \\
\hline Carbohydrate (g) & 143.8 & 28.4 & 20.9 \\
\hline Dietary Fibre (g) & 13.7 & 3.7 & 27.5 \\
\hline Sodium (mg) & 1021 & 91.9 & 11.0 \\
\hline Calcium (mg) & 908 & 302 & 35.1 \\
\hline Iron $(\mathrm{mg})$ & 10.5 & 4.3 & 40.1 \\
\hline Zinc (mg) & 7.2 & 3.0 & 41.2 \\
\hline Thiamin (mg) & 1.1 & 0.2 & 19.0 \\
\hline Riboflavin (mg) & 1.6 & 0.4 & 29.6 \\
\hline Total Niacin (mg) & 19.3 & 2.1 & 11.6 \\
\hline Folate $(\mu \mathrm{g})$ & 187 & 44.2 & 25.0 \\
\hline Vitamin A $(\mu \mathrm{g})$ & 1000 & 221 & 27.8 \\
\hline Vitamin C (mg) & 114 & 49.3 & 44.0 \\
\hline Vitamin $\mathrm{D}(\mu \mathrm{g})$ & 8.6 & 5.7 & 69.4 \\
\hline Vitamin B6 (mg) & 1.3 & 0.2 & 13.4 \\
\hline Vitamin B12 $(\mu \mathrm{g})$ & 3.7 & 0.5 & 18.3 \\
\hline
\end{tabular}

Relative to energy, growing-up milks contributed a greater proportion of the mean daily intakes of dietary fibre, calcium, iron, zinc, riboflavin, vitamin A, vitamin C and vitamin D, a lower proportion of protein, saturated fat, sodium, niacin and vitamin B6, and similar proportions of carbohydrate, fat, thiamin, folate and vitamin B12. Growing-up milks make an important contribution to overall dietary balance and serve as a rich source of critical nutrients such as iron and vitamin D for which there is a risk of inadequacy in this age group.

The project was funded by the Irish Government under the Food for Health Research Initiative 2007-2012 and Danone Baby Nutrition.

1. Food Standards Agency (2002) McCance \& Widdowson's The Composition of Foods Fifth \& Sixth Editions including supplemental volumes. Cambridge: Royal Society of Chemistry.

2. Black LJ, Ireland J, Møller A, Roe M, Walton J, Flynn A, et al. (2011) Development of an on-line Irish food composition database for nutrients. J Food Compos Anal 24(7), 1017-1023. 